\title{
Crude Distillation Unit (CDU) dari Kuwait Crude Oil
}

\author{
Ryanda Luthfi Zaim, Wahyuni Eka Muqni, Siti Nurkhamidah, Yeni Rahmawati dan Soejoto Gondo \\ Departemen Teknik Kimia, Fakultas Teknologi Industri, Institut Teknologi Sepuluh Nopember (ITS) \\ e-mail: dst_eureka@yahoo.co.uk
}

\begin{abstract}
Abstrak-Kebutuhan Indonesia akan energi terus meningkat. Produksi energi dalam negeri jika dilihat dari kapasitas kilang yang tersedia tidak sebanding dengan konsumsi masyarakat. Oleh karena itu, perlu dibangun sebuah pabrik untuk memenuhi kekurangan dari produksi energi tersebut. Pada perencanaan ini akan dibangun pabrik crude distillation unit (CDU) dengan kapasitas 300000 barrel per hari. Prinsip kerja dari CDU adalah proses pemisahan berdasarkan titik didih komponenkomponennya pada tekanan atmosferik. Bahan baku yang digunakan dalam proses ini adalah Kuwait crude oil. Kuwait crude oil merupakan salah satu Negara dengan jumlah minyak mentah (crude oil) terbesar didunia serta memiliki jumlah ekspor sebesar 50\% dari total produksi. Produk yang dihasilkan dari pabrik CDU berupa naphtha (overhead product), kerosene, light gas oil, heavy gas oil dan long residu. Berdasarkan analisis yang telah dilakukan dari segi teknis berupa kapasitas produksi, umur pabrik dan perencanaan produksi serta dari ekonomi berupa IRR sebesar 9\%, POT selama 10,2 tahun dan BEP sebesar $75 \%$ maka diperoleh hasil bahwa pabrik CDU layak didirikan.
\end{abstract}

Kata Kunci-crude oil, crude distillation unit, heaavy gas oil, kerosene, light gas oil, long residu.

\section{PENDAHULUAN}

$\mathrm{I}$ NDONESIA memiliki cadangan minyak yang tersebar di beberapa daerah. Namun candangan minyak bumi Indonesia semakin menurun seiring dengan bertambahnya waktu. Minyak bumi (crude oil) dapat diolah menjadi sumber energy yang digunakan oleh masyarakat. Kebutuhan masyarakat akan energy terus meningkat sebanding dengan jumlah penduduk yang terus bertambah tiap tahunnya hingga saat ini mencapai angka 1.600 .000 barrel per hari. Kapasitas kilang terpasang di Indonesia saat ini sebesar 1.000 .000 barrel per hari. Dari kedua nilai tersebut terlihat bahwa Indonesia masih membutuhkan supply energy sebesar 600.000 barrel per hari. Oleh karena itu akan didirikan kilang dengan kapasitas 300.000 barrel per hari untuk memenuhi kebutuhan masyarakat. Sedangkan jika ditinjau dari minyak bumi dalam negeri hanya tersedia sekitar 600.000 barrel per hari. Jumlah tersebut tidak dapat memenuhi kebutuhan kilang yang ada di Indonesia, sehingga perlu dilakukan import minyak mentah (crude oil) untuk mengisi kekurangan produksi dalam negeri.

Crude oil merupakan sumber energi yang diolah untuk menghasilkan beberapa produk. Energi sangat diperlukan dalam menjalankan aktivitas perekonomian Indonesia, baik untuk kebutuhan konsumsi maupun untuk aktivitas produksi berbagai sektor perekonomian. Sebagai sumber daya alam, energi harus dimanfaatkan sebesar-besarnya bagi kemakmuran masyarakat dan pengelolaannya harus mengacu pada asas pembangunan berkelanjutan. Dari aspek penyediaan, Indonesia merupakan negara yang kaya dengan sumberdaya energi baik energi yang bersifat unrenewable resources maupun yang bersifat renewable resources. Namun demikian, eksplorasi sumberdaya energi lebih banyak difokuskan pada energi fosil yang bersifat unrenewable resources sedangkan energi yang bersifat renewable relatif belum banyak dimanfaatkan. Kondisi ini menyebabkan ketersediaan energi fosil, khususnya minyak mentah, semakin langka yang menyebabkan Indonesia saat ini menjadi net importir minyak mentah dan produk-produk turunannya.

Minyak mentah (crude oil) yang digunakan dalam proses pabrik CDU adalah Kuwait crude oil. Kuwait crude oil memproduksi minyak mentah sebesar 2.858 .700 barrel per hari dimana $50 \%$ dari total produksi akan diekspor yakni sebesar 1.963 .800 barrel per hari.

Crude Distillation Unit (CDU) memiliki prinsip kerja yakni pemisahan komponen-komponen minyak bumi berdasarkan titik didih nya pada tekanan atmosferik. Produk dari Crude Distillation Unit (CDU) adalah naphtha (overhead product), kerosene, light gas oil, heavy gas oil dan long residu. Produk CDU akan menjadi intermediate product bagi pengolahan crude oil sekaligus feed bagi unit pengolahan lain seperti Naphta Hydrotreater, Kerosene Hydrotreater, Gas Oil Hydrotreater, dan lain-lain. Produk CDU yang dihasilkan akan diolah lebih lanjut untuk mendapatkan produk akhir seperti LPG, gasoline, avtur, diesel, lube base oil, aspal dan lain-lain. Berikut adalah cut range dari masing-masing produk yang dihasilkan oleh pabrik CDU:

Tabel 1.

Cut Range masing-masing produk pabrik CDU

\begin{tabular}{cc}
\hline \hline Jenis Produk & Cut Range $\left({ }^{\circ} \mathrm{C}\right)$ \\
Naphtha (Overhead Product) & C5+-175 \\
\hline Kerosene & $175-250$ \\
Light Gas Oil & $250-300$ \\
Heavy Gas Oil & $300-350$ \\
Long Residu & $350+$ \\
\hline \hline
\end{tabular}

\section{URAIAN PROSES}

\section{A. Spesifikasi Bahan Baku}

Bahan baku yang diolah adalah kuwait crude oil dengan spesifikasi berupa derajat API, viskositas kinematic, pour 
point, freezing point serta kadar air dan kadar sulfur masing masing adalah $31,42,10,8,37,8^{\circ} \mathrm{F}, 49,5^{\circ} \mathrm{F}, 0,15 \%$ wt dan $3,85 \%$ wt. Berikut adalah tabel \%volume distilled dengan true boiling point.

Tabel 2.

True Boiling Point Kuwait Crude Oil

\begin{tabular}{cc}
\hline \hline \%Volume distiled & TBP $\left({ }^{\circ} \boldsymbol{F}\right)$ \\
\hline IBP & -127 \\
$5 \%$ & 33.5 \\
$10 \%$ & 194 \\
$20 \%$ & 300.2 \\
$30 \%$ & 422.6 \\
$40 \%$ & 545 \\
$50 \%$ & 653 \\
$60 \%$ & 788 \\
$70 \%$ & 919.4 \\
$80 \%$ & 1058 \\
$90 \%$ & 1220 \\
$95 \%$ & 1706 \\
FBP & 2192 \\
\hline
\end{tabular}

\section{B. Lokasi Pabrik}

Pemilihan lokasi pabrik didasarkan pada beberapa hal yaitu kedekatan lokasi pabrik dengan konsumen, tersedianya tenaga kerja, kondisi geograis, ketersediaan air, transportasi dan sumberbahan baku. Berdasarkan hal tersebut maka dipilihlah Tuban sebagai lokasi pendirian pabrik Crude Distillation Unit dari Kuwait Crude Oil.

\section{Persiapan Bahan Baku}

Pada tahap ini, Kuwait crude oil dialirkan melalui beberapa heat exchanger (E-111 A/B/C) menuju desalter. Crude oil memasuki unit desalter pada suhu $248^{\circ} \mathrm{F}$. Crude oil memasuki desalter untuk dikurangi kandungan garamnya hingga maksimal 0.05 ptb. Desalter berfungsi untuk mengurangi kandungan garam hingga mencapai minimal $95 \%$ dengan penambahan fresh water. Fresh water digunakan untuk mengencerkan high salt content brine menjadi low salt content water. Kemudian ditambahkan deemulsifier yang bertujuan untuk memecahkan emulsi antara air dan minyak sehingga air akan berada pada bagian bawah desalter. Pada desalter, minyak dikenakan medan elektrik yang bertegangan tinggi sehingga air menggumpal dan mengendap pada dasar tangki sedangkan minyak berada pada bagian atas tangki. Ketinggian air pada tangki diatur dengan system pengendali ketinggian. Desalter beroperasi pada temperature dan tekanan sekitar $120^{\circ} \mathrm{C}$ dan tekanan 6.3 bar. Minyak keluaran desalter dipompa dan mengalami preheating $(\mathrm{E}-121 \mathrm{~A} / \mathrm{B} / \mathrm{C})$ hingga suhu $235^{\circ} \mathrm{C}$ sebelum memasuki furnace.

Crude oil dalam furnace (Q-120) akan dipanaskan hingga suhu $760{ }^{\circ} \mathrm{C}$. Pemanasan tersebut dilakukan sebelum memasuki flash zone CDU dimana sekitar 66\% minyak teruapkan. Crude oil yang tidak teruapkan adalah residu yang akan dioleh lebih lanjut lagi menjadi fuel oil atau yang lainnya.

\section{Proses Distilasi}

Crude oil dari furnace kemudian dialirkan kedalam kolom distilasi. Tekanan kolom ialah $5-10$ psig atau $1.13-1.34$ atm gauge. Crude oil saat memasuki kolom distilasi pada temperatur flash zone yaitu pada temperatur $760^{\circ} \mathrm{F}$. Produk pada kolom distilasi akan dikondensasikan menjadi naphtha (overhead product), light gas oil, heavy gas oil, kerosene dan long residu pada tray yang berbeda-beda berdasarkan titik didih.

Minyak memasuki kolom distilasi dimana 53\% dari minyak akan menguap menuju bagian atas kolom dan $47 \%$ menuju bagian bawah kolom yang disebabkan oleh perbedaan tekanan antara furnace dan kolom distilasi. Stripping steam diinjeksikan ke dalam kolom untuk pelucut dengan menurunkan tekanan uap parsial dari hidrokarbon sehingga fraksi ringan dapat terbawa oleh steam ke bagian atas kolom. Steam yang digunakan adalah steam kering, digunakan untuk menghindari tekanan total yang besar pada kolom fraksinasi. Bila steam yang masuk mengandung air, sedangkan suhu kolom fraksinasi lebih tinggi dari suhu steam, maka air yang masuk akan menguap dalam kolom fraksinasi sehingga akan memperbesar tekanan total. Bagian bawah kolom diisi dengan long residu dengan temperature $740^{\circ} \mathrm{F}$. Residu tersebut akan memanaskan minyak sebelum masuk kedalam kolom distilasi sehingga temperature nya menurun untuk diolah lebih lanjut lagi pada unit yang berebeda. Dalam kolom fraksinasi ini juga terdapat adanya pumparound, yaitu mengambil sebagian liquid dari kolom kemudian didinginkan dan dikembalikan lagi ke kolom. Tujuannya adalah untuk mengembunkan kembali fraksi yang tidak seharusnya menguap.

Uap dalam kolom distilasi akan dikondensasikan pada masing-masing tray, kemudian yang terkondensasi akan keluar menjadi side stream sedangkan uap yang tidak terkondensasi dialirkan kembali ke dalam kolom dan menuju bagian atas kolom. Uap yang berada pada bagian atas kolom distilasi terdiri dari semua jenis hidrokarbon. Selanjutnya uap akan didinginkan dan dikondensasikan dengan air cooler dan water condenser sebelum memasuki receiver drum. Dalam receiver, terjadi pemisahan antara kondesat dan uap yang tidak terkondensasi. Kondensat sebagian diairkan kedalam recontact drum dan sebagian lagi akan dikembalikan kedalam kolom distilasi sebagai reflux. Sedangkan uap yang tidak terkondensasi dialirkan menuju knock out drum untuk dipisahkan lebih lanjut antara liquid yang terikut pada gas dan gas itu sendiri dengan bantuan dari mis eliminator. Liquid yang terpisah pada knock out drum akan dikembalikan ke dalam receiver sedangkan gas akan dikompresi untuk selanjutnya memasuki recontact drum. Pada recontact drum, gas akan dikontakkan dengan liquid dari receiver agar liquid dapat menyerap komponen butane dan propane yang masih terikut pada gas. Produk liquid dari recontact akan dioleh lebih lanjut pada unit selanjutnya untuk dipisahkan antara lpg dan naphtha. Sedangkan gas akan keluar sebagai off gas.

Produk samping bagian atas berupa kerosene yang memiliki TBP (true boiling point) sekitar $150-250^{\circ} \mathrm{C}$. Kerosene sirkulasi 
digunakan untuk memanaskan crude kemudian dikambalikan lagi kedalam kolom. Produk kerosene akan melalui stripper dimana terjadi proses pemanasan sehingga fraksi ringan akan menguap dan dikembalikan ke kolom. Produk kerosene yang keluar dari stripper memiliki suhu yang cukup tinggi maka digunakan untuk memanaskan crude oil sehingga suhunya menurun. Produk kerosene kemudian masuk ke tangki penyimpanan.

Light Gas Oil (LGO) memiliki TBP sekitar $250-300^{\circ} \mathrm{C}$. Sekitar 30\% cairan akan dikembalikan ke kolom tanpa melalui pendinginan sedangkan sekitar $60 \%$ akan melalui pendinginan sehingga terjadi penurunan suhu. LGO sirkulasi digunakan untuk memanaskan minyak hingga suhu menurun dan dikembalikan kedalam kolom. Produk LGO akan melalui stripper sehingga fraksi ringan akan menguap dan dikembalikan ke kolom. Produk LGO yang keluar dari stripper akan memanaskan crude oil dan melalui pendingin udara (finfan cooler) sehingga temperature nya menurun.

Heavy Gas Oil (HGO) memiliki TBP sekitar $300-350^{\circ} \mathrm{C}$. Sebanyak $45 \%$ cairan ber suhu tinggi dikembalikan ke kolom langsung tanpa pendinginan dan $40 \%$ cairan didinginkan terlebih dahulu kemudian dikembalikan ke kolom. HGO sirkulasi digunakan untuk menyediakan panas penguapan pada Kerosene stripper. Produk HGO akan memasuki HGO stripper untuk menghilangkan fraksi ringan. Selanjutnya HGO akan didinginkan dengan menggunakannya sebagai fluida pemanas untuk crude oil dan pendingin udara hingga mencapa suhu yang diinginkan.

Pada kolom stripper HGO diinjeksikan steam yang sama seperti pada kolom fraksinasi utama, sedangkan pada stripper Kerosene dan LGO tidak digunakan steam namun digunakan reboiler, hal ini karena pertimbangan efisiensi, jika terlalu banyak steam yang diinjeksikan maka akan banyak air yang terkandung dalam minyak dan akan mempersulit proses pemisahannya. Selain itu juga atas pertimbangan titik didih dari kerosene yang rendah, sehingga cukup hanya digunakan closed steam saja. Prinsip utama dari kolom stripper adalah untuk memisahkan produk yang diinginkan dari komponen yang lebih ringan. Dan untuk efisiensi, maka produk yang dihasilkan digunakan sebagai media pemanas dan heat exchanger seperti yang telah disebutkan sebelumnya.

Long residu dialirkan ke vacuum distillation unit untuk melalui pengolahan lebih lanjut atau dapat juga diolah sebagai fuel oil.

\section{NERACA MASSA}

Bahan baku (crude oil) yang digunakan sebesar 300000 BPSD akan diolah menjadi bebrapa produk berupa naphtha (overhead product), kerosene, light gas oil, heavy gas oil dan long residu dengan jumlah masing masing adalah 71976.4 BPSD, 32989.2 BPSD, 26991.2 BPSD, 26991.2 BPSD dan 1140954 BPSD. Sedangkan sebagian kecil dari crude yang masuk adalah impurities yang telah dipisahkan pada tahap persiapan bahan baku.

\section{ANALISA EKONOMI}

Analisa ekonomi merupakan salah satu parameter apakah suatu pabrik tersebut layak didirikan atau tidak. Untuk menentukan kelayakan suatu pabrik secara ekonomi, diperlukan perhitungan bahan baku yang dibutuhkan dari produk yang dihasilkan menurut neraca massa. Harga peralatan untuk proses berdasarkan spesifikasi peralatan. Parameter kelayakan tersebut antara lain POT (Pay Out Time), Internal Rate of Return (IRR) dan BEP (Break Event Point).

Berdasarkan analisa yang dilakukan diperoleh hasil berupa POT selama 10.2 tahun, IRR sebesar 9\% dan BEP sebesar $76.08 \%$ dimana bentuk perusahaan yang digunakan adalah perseroan terbatas (PT) dengan umur pabrik selama 20 tahun.

\section{KESIMPULAN/RINGKASAN}

Berdasarkan analisis yang telah dilakukan, maka perencanaan operasi crude distillation unit (CDU) dilakukan secara kontinyu, 24 jam dan 330 hari/tahun dengan jumah tenaga kerja sbanyak 256 orang dan kapasitas produksi sebesar 300000 barrel per hari serta umur pabrik selama 20 tahun. Dari hasil analisis ekonomi yang dilakukan didapatkan hasil yaitu IRR sebesar 9\%, POT sebesar 10,2 tahun serta BEP sebesar 76,08 \%. Berdasarkan analisis dari segi ekonomi dan teknis maka pabrik crude distillation unit ini layak untuk didirikan.

\section{DAFTAR PUSTAKA}

[1] Brownell, Lloyd E. dan Edwin H. Young, "Process Equipment Design", John Wiley \& Sons, New York, 1959.

[2] Geankoplis, Christie J., "Transport Processes and Unit Operations", 3rd edition, $\quad$ Prentice-Hall of India, New Delhi, 1997.

[3] Kementrian Energi dan Sumber Daya Mineral,'Indonesia Energy Outlook", Pusat Data Kementrian Energi dan Sumber Daya Mineral, Jakarta, 2010

[4] Kementrian Energi dan Sumber Daya Mineral,"Handbook of Energy and Economic Statistic Indonesia", Pusat Data Kementrian Energi dan Sumber Daya Mineral, Jakarta,2017.

[5] Jones, David S. J."Handbook of Petroleum Processing". Springer, USA, 2006

[6] Kern, Donald Q., "Process Heat Transfer", International Edition, McGraw-Hill Book Company, Tokyo, 1965.

[7] Kusnarjo, "Desain Bejana Bertekanan", 2010.

[8] Ludwig. E. Ernest "Design For Chemical and Petrochemichal Plants".,Gull Publishing Houston-Texas, 1947

[9] McCabe, W.L., dan J.C. Smith. Unit Operation of Chemical Engineering. Singapore: McGraw-Hill International Book Company. 1985.

[10] Meyers, Robert A, 'Handbook of Petroleum Refining Processes", 3th edition, McGraw Hill, USA, 1978.

[11] Peters, Max S., Klaus D. Timmerhaus, dan Ronald E. West, "Plant Design and Economics for Chemical Engineers", 5th edition, McGraw-Hill Book Company, Boston, 2003.

[12] Perry, Robert H. and Don Green, "Perry's Chemical Engineers' Handbook", 7th edition, McGraw-Hill Book Company, New York.

[13] Putra, Zulfan Adi. "Buku Pintar Migas Indonesia".Migas Indonesia, Indonesia, 2007.

[14] Smith, Robin.,"Chemical Process Design",McGraw Hill International Book Company, Singapore, 1955.

[15] Ulrich, Gael D., "A Guide to Chemical Engineering Process Design and Economic", John Wiley \& Sons, Canada, 1984. 
[16] Van Ness, Smith, "Introduction to Chemical Engineering Thermodynamics", 4th edition, International edition, McGraw Hill Inc, Singapore, 1967.

[17] Van Winkle, Matthew.,"Distillation",McGraw Hill Book Company, New York, 1967. 